\title{
URBAN SPACE DIVERSITY IN SOUTH AFRICA: MEDIUM DENSITY MIXED DEVELOPMENTS
}

\author{
Karina Landman
}

\begin{abstract}
As is the case internationally, there is also an increased focus on urban space diversity in South Africa. Is it appropriate to pursue place diversity in South Africa? If so, what are the design factors that support place diversity and can these be accommodated by the development of medium density mixed housing in the country? Furthermore, could these emerging trends be considered as part of a larger global trend moving towards greater place diversity in cities, or does it only offer local fragments and practices of fashionable international ideas? This paper explores the multiple meanings of place diversity in the country as evident in the development of medium density mixed housing developments and highlights a number of paradoxes that emerge as a result of the context-specific realities.
\end{abstract}

Keywords: Space diversity, medium density mixed housing, South Africa.

\section{INTRODUCTION}

In reaction to the continuous challenges posed by social and spatial segregation in contemporary cities, there has been an increasing call for greater social and spatial integration and mixed developments in recent years in countries such as the in USA (Brophy and Smith, 1997), UK (Berube, 2005), Netherlands (Geurs and Van Wee, 2006), Germany (Hanhorster, 2001), Australia (Johnston, 2002) and New Zeeland. It is argued that mixed neighbourhoods can support place diversity and contribute to safer and more sustainable human settlements (Jacobs, 1961; Rogers, 1997; Jenks and Dempsey, 2003; Jabareen, 2006; Talen, 2008). Place diversity exists within the realm of 'everyday life' activities and are described as "places with socially diverse people sharing the same neighbourhoods, where diversity is the result of a mix of income levels, races, ethnicities, ages, and family types" (Talen, 2008: 45). The pursuit of greater diversity is also supported in major contemporary urban design and planning movements such as New Urbanism, Traditional Neighbourhood Development and Smart Growth.

Urban space diversity is also a key concern in South Africa. In spite of this, there is not always agreement on the meaning of diversity in the country or how this should be achieved in practice.
While almost all built environment professionals and urban practitioners agree that there is a need to facilitate the achievement of greater socio-spatial diversity, many question the viability thereof within the South African context given the legacy of separate development, oppression, domination, exclusion and segregation - many of the scars of which are still all too prevalent within urban environments.

In South Africa, the national housing plan (2004) promotes the implementation of medium density and mixed housing to address the segregated development patterns. Looking at the nature and impact of these developments in the country, the question is whether medium density mixed housing is likely to support the creation of place diversity in South Africa. This paper aims to conceptualise urban space diversity and investigate these multiple meanings of diversity within the South African context. It explores to what extent it is possible to plan and/or design for diversity through an investigation of the design strategies used in multiple case studies on medium density mixed housing developments. In doing so, the discussion highlights the various paradoxes and realities evident in the development of these new developments to promote diversity. 


\section{MULTIPLE MEANINGS OF URBAN SPACE DIVERSITY}

\section{What is diversity?}

There are many interpretations of diversity, ranging from a focus on mixed social and ethnic groups (Hanhorster, 2001) and a diversity of economic opportunity (Quigley, 1998), to a focus on the physical elements and 'good urban form' that promote place diversity (Talen, 2008). The need to focus on planning and design that supports greater diversity and socio-spatial mix, has long been a concept embedded in city planning and design idealism, ranging from Howard's call for the provision of neighbourhoods and towns to provide the diverse and essential needs of life, to Mumford and Whyte highlighting the nature of the physical context and its link greater diversity. From these debates on new directions for urban development and planning and the re-design of urban space, two key design factors stand out as being connected to greater diversity, namely socio-spatial mix and density. Socio-spatial mix and socially diverse neighbourhoods can be related to a number of factors including historical/ economical/social, policyrelated and physical/location; each having an interrelated effect on one another (Talen, 2008). Density also has an impact on diversity. Jacobs (1961) preferred densities in the range of 100 du/acre $(247 \mathrm{du} / \mathrm{ha})$ and maintained that higher densities and ground cover, facilitated through smaller urban blocks and a variation of building types, would positively influence population and economic diversity. However, as Talen (2008) points out, density and diversity is not always correlated as attempts towards densification and consequent gentrification may lead to the displacement of lower-income households.

\section{Why diversity in cities or neighbourhoods?}

Place diversity is therefore generally concerned with the creation of more opportunities for a variety of people in closer proximity. Jacobs (1961) considers diversity as a vital part of successful cities; without it the urban system will not provide an adequate place to live. Talen (2008) maintains that place diversity is generally linked to place vitality and social equity. Place vitality is concerned with economic health and sustainability and social equity relates to access ('geography of opportunity') and the utopian ideal where a mix of populations groups are considered as the basis for a more creative, tolerant and stable world (Talen, 2008). A recent study in the UK identified a number of benefits of a mixed community, namely that residents of all ages, ethnic groups and social classes have the opportunity to interact; the potential for negative-area effects, such as low-level crime, is reduced; local schools can attract students from a wide range of backgrounds; mixed-income areas may be able to attract and support a higher level of local services, recreational and entertainments facilities and a variety of shops; residents have the opportunity to move within the development to accommodate changing needs, while still maintaining social networks; and higher average levels of disposable income may create additional employment opportunities for local residents (Baily et al 2006: 20).

However, "if a development is not diverse, then homogeneity of built forms often produces unattractive, monotonous urban landscapes, a lack of housing for all income groups, class and racial segregation, and job-housing imbalances that lead to increased driving, congestion, and air pollution" (Wheeler, 2002: 328). This has been the case in South Africa where cities have been characterised by low-density sprawl, fragmentation and separation in the early nineties. Low-density sprawl manifested in three processes that determined the pattern of growth: speculative sprawl, the development of low-cost housing schemes on the urban peripheries; and illegal squatting. Fragmentation was caused by a cellular development pattern with neighbourhoods organised in relatively discrete cells, frequently bound by freeways and/or buffers of open space. The third pattern is separation, which included separation of land uses, races and income groups to the greatest degree possible (Dewar, 1992).

\section{Design for diversity}

A number of authors have outlined strategies to plan and design for more diverse neighbourhoods (including Jacobs, 1961; Jenks and Dempsey, 2004; Jabareen, 2006). Talen (2008) summarises the debates and presents three over-arching design strategies for greater diversity: mix, connection and 
security. The first refers to socio-spatial mix through a mix of housing types (form, size and tenure), housing ages and facilities and services mix and policies that promote mixed developments. The second strategy relates to the connectivity of different types of urban spaces, which is linked to the identity of spaces, collective space, access to different institutions and a variety of networks. The third strategy deals with the challenge to promote creativity and mix, without increased tension and conflict, which will imply housing integration, opportunities for surveillance, spaces for positive activity (i.e. avoiding 'dead' space) and providing strong and desirable edges to diverse places.

These strategies can also differ from place to place. In South Africa, government policies have reacted against the spatial patterns of low density sprawl, fragmentation and separation. In this context, the new housing plan presents alternative options for delivery with an emphasis on restructuring the city. The emphasis is on the creation of sustainable settlements as environments for diversity and choice offered by a range of housing options in close proximity to supporting facilities, amenities and economic opportunities (South African Housing Department, 2004).

\section{DIVERSITY IN MEDIUM DENSITY MIXED DEVELOPMENTS}

\section{Research background}

The findings are based on multiple case studies of medium density mixed housing projects. The case studies included two components: firstly investigating the context, namely the socio-spatial environment and secondly understanding the views of key stakeholders, including the residents, developers, financiers and housing officials. A number of methods and tools were used to investigate these issues, such as a spatial analysis tool to assess the physical context, a structured questionnaire to conduct household surveys ${ }^{1}$ with a sample of residents and semi-structured interviews with developers, officials and financiers (for a detailed discussion see Landman and Du Toit, 2008). The original project included two pilot case studies and five additional

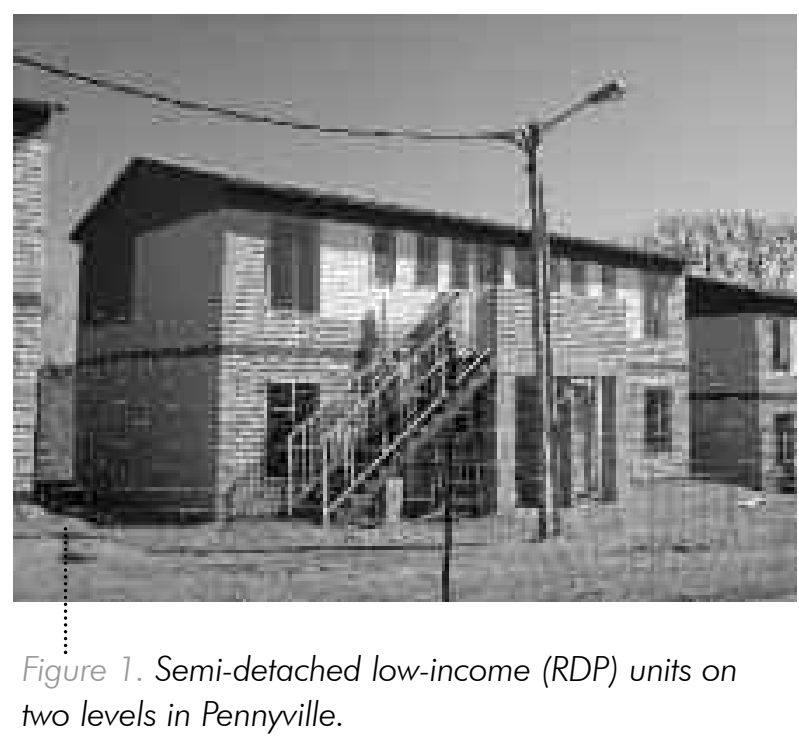

cases across the country. The methodology was repeated in four additional cases in 2010 by a number of final year planning students from the University of Pretoria. The paper subsequently focuses on the findings from these 11 cases across South Africa ${ }^{2}$.

\section{Design strategies}

This section utilises Talen's (2008) three main design strategies, mix, connectivity and security, to explore the diversity present in medium density mixed developments in South Africa. Although the degree varies, all of the cases have a mix of housing types, including the form, size and/or tenure. These vary from a mix of unit types and sizes within different multi-story buildings, for example Amalinda, Brickfields, Carr Gardens and Melrose Arch, to a combination of different sizes of houses for various income and tenure groups in an urban block or precinct, for example Cosmo City, Pennyville, Olievenhoudtbosh, Thornhill and Wonder Park. The housing types also vary from semi-detached or row houses to single houses on a plot (Figures 1 and 2). As these are all relatively newly built developments, there is not a mix of housing ages. All of these developments have some form of communal facility, ranging from a community centre/ facilities and crèche to a large variety of land use mix, for example Melrose Arch.

The second strategy relates to the connectivity of different types of urban spaces. The identity

${ }^{1}$ Structured questionnaires were distributed to a sample of households (minimum 30 households but up to 60 in larger developments) in each of the case study areas. The questionnaire included a section to obtain demographic information, including household income, a section obtaining the resident's views on the critical success factors and three open ended questions at the end to obtain any additional information that may not have been covered in the structured questions; thus including both closed and open questions, which facilitated both quantitative and qualitative data analysis. 


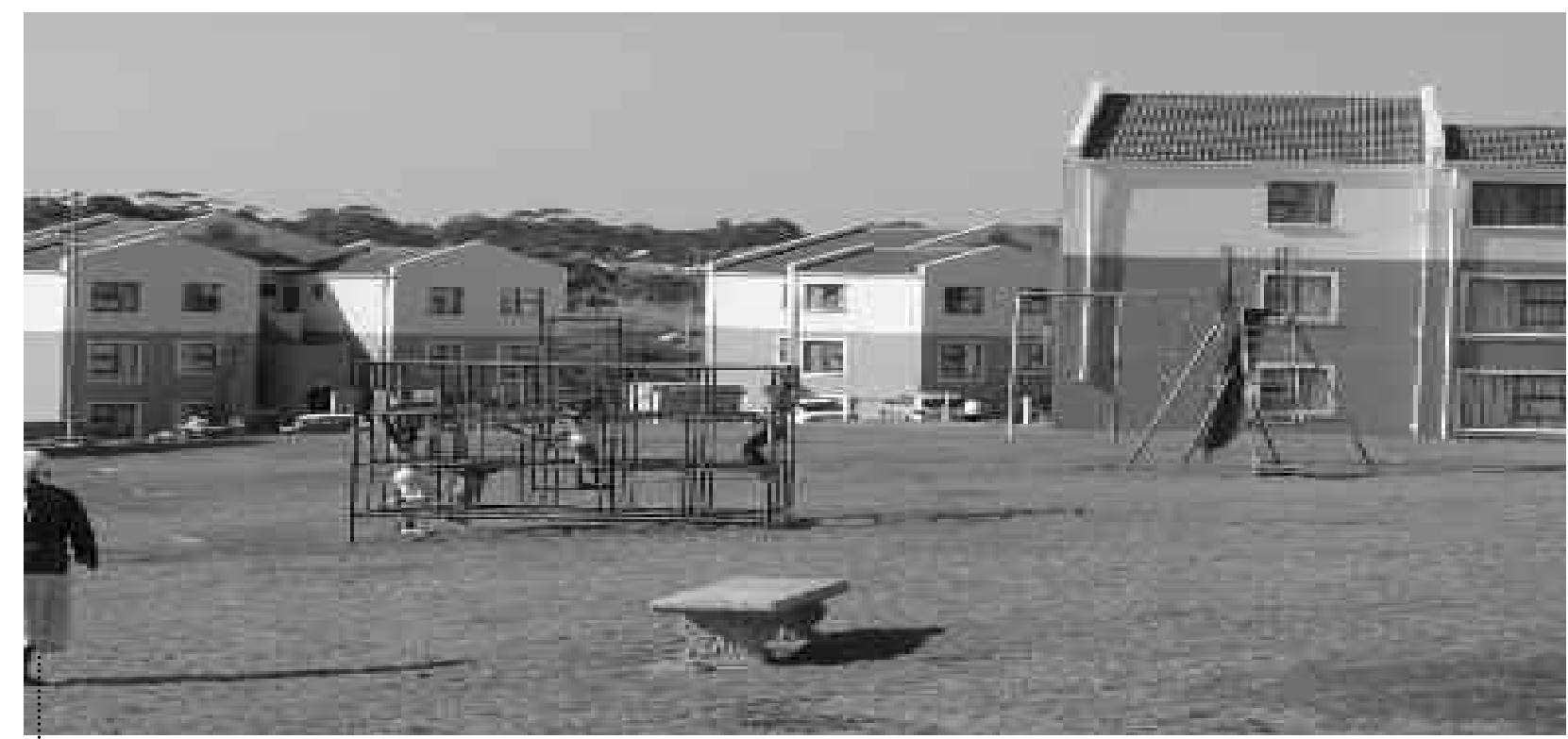

Figure 2. Different building types and unit sizes organised around communal play space in Amalinda.

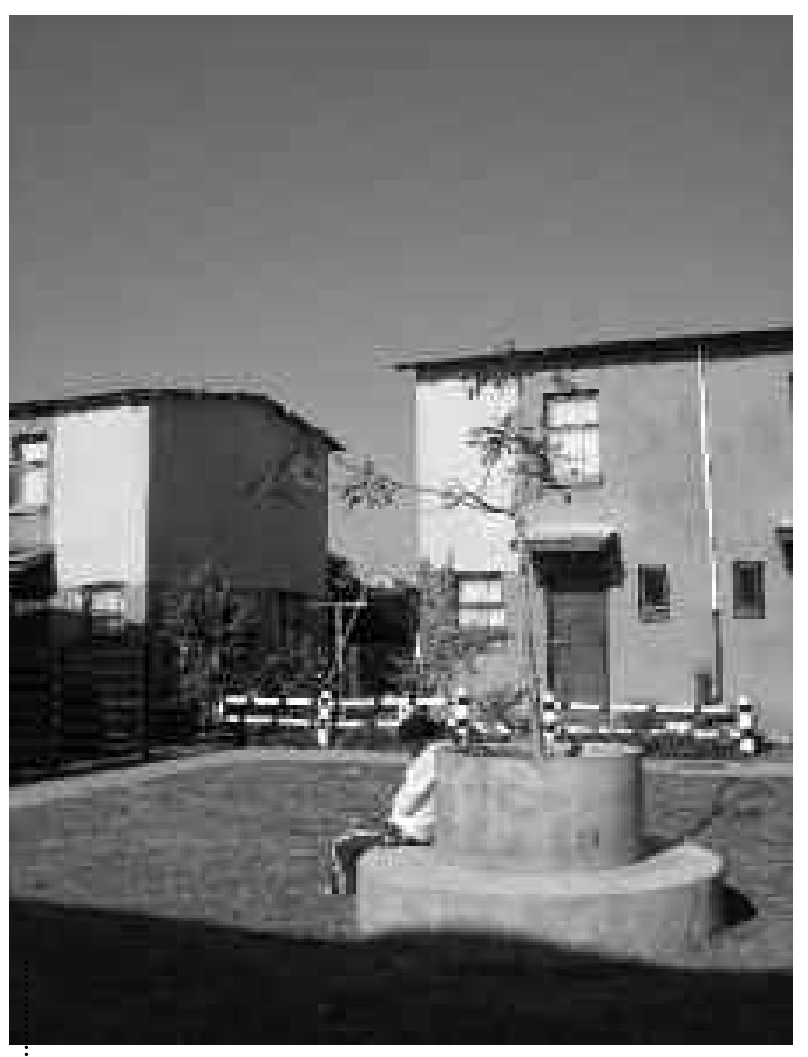

Figure 3. Small neighbourhood/ communal spaces in Sakhasonke.

of spaces is linked to the images, symbols and landmarks of a neighbourhood that serve to hold together a diverse population (Talen 2008: 152). This varies in the different projects. While the identity is not strong in some cases, the small neigh- bourhood parks with characteristic bench and plant holders in Sakhasonke (Figure 3) and the specific design and signs in the parks in Cosmo City (Figure 4) provides identity to these spaces. The street furniture, sculptures and landscape features in Melrose Arch provides a strong sense of identity and offers collective space to the residents and visitors. Access to different institutions and a variety of networks also differs depending on the target-group and levels of affordability related to the development and the size of the area. The larger neighbourhoods include a range of institutions, while the smaller developments only feature a community centre / facilities and/or crèche. The design of Sakhasonke and Melrose Arch gave the most attention to the provision of pedestrian routes.

The third strategy deals with the challenge to promote creativity and mix, while ensuring security. The layout of roads and housing units allows moderate to good opportunities for surveillance in most of the cases, with a conscious attempt to avoid 'dead' space. However, due to the phasing of large projects such as Cosmo City, Pennyville and Olievenhoudtbosh, there are still some vacant sites which provide opportunities for crime, such as mugging and rape, when people are forced to cross these spaces early in the morning or late at night. The provision of strong edges raises an inter-

\footnotetext{
2 The cases were selected based on a set of criteria, namely that they encompass a medium density of about 50 - $125 \mathrm{du} / \mathrm{ha}$ and at least two forms of mix (housing units/types; tenure; income and/or land use) within a low-rise development. The case studies are distributed throughout the country and indicates that 'medium density mixed housing' can differ quite extensively in practice in terms of size, built form and types of mix involved, while still broadly adhering to the criteria.
} 


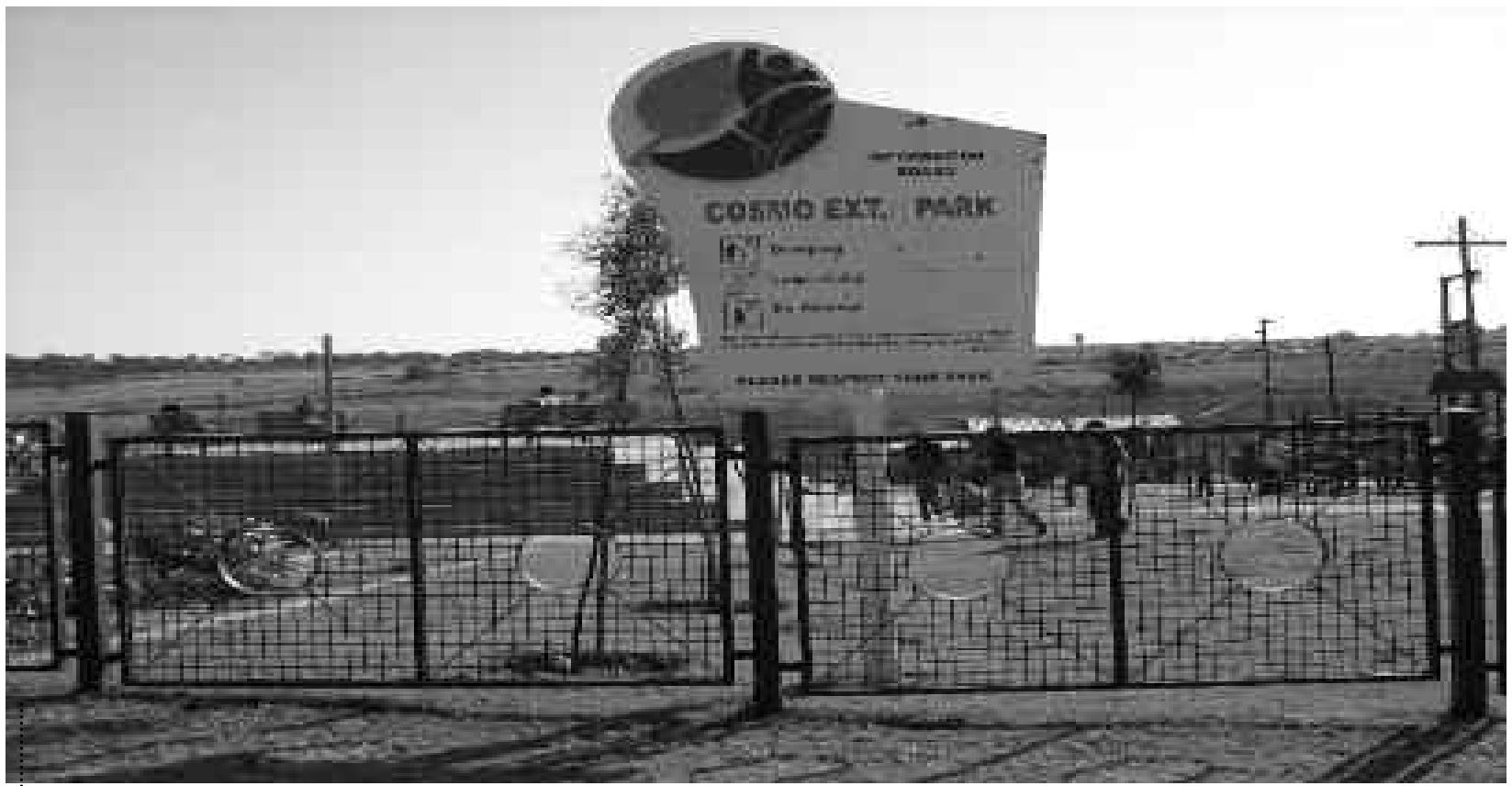

Figure 4. Neighbourhood park in Cosmo City.

esting dilemma in South Africa, where many of the residents associate a strong edge with a hard boundary in the form of a wall or fence. Target hardening has been voiced as a key concern in most of the projects and hence developers provided these hard edges where possible - strengthening the boundaries even further through access control in some cases.

\section{Social mix}

The medium density mixed housing projects facilitated opportunities for social mix through a mix of income groups, age groups and to some extent a mix of population groups. Following the findings from the initial pilot case studies (Brickfields and Carr Gardens) the questionnaire was adapted to accommodate a larger band of income groups. This revealed a reasonable spread of income groups across the income bands (Figure 5) ${ }^{3}$. Apart from Sakhasonke, which was intended to accom-

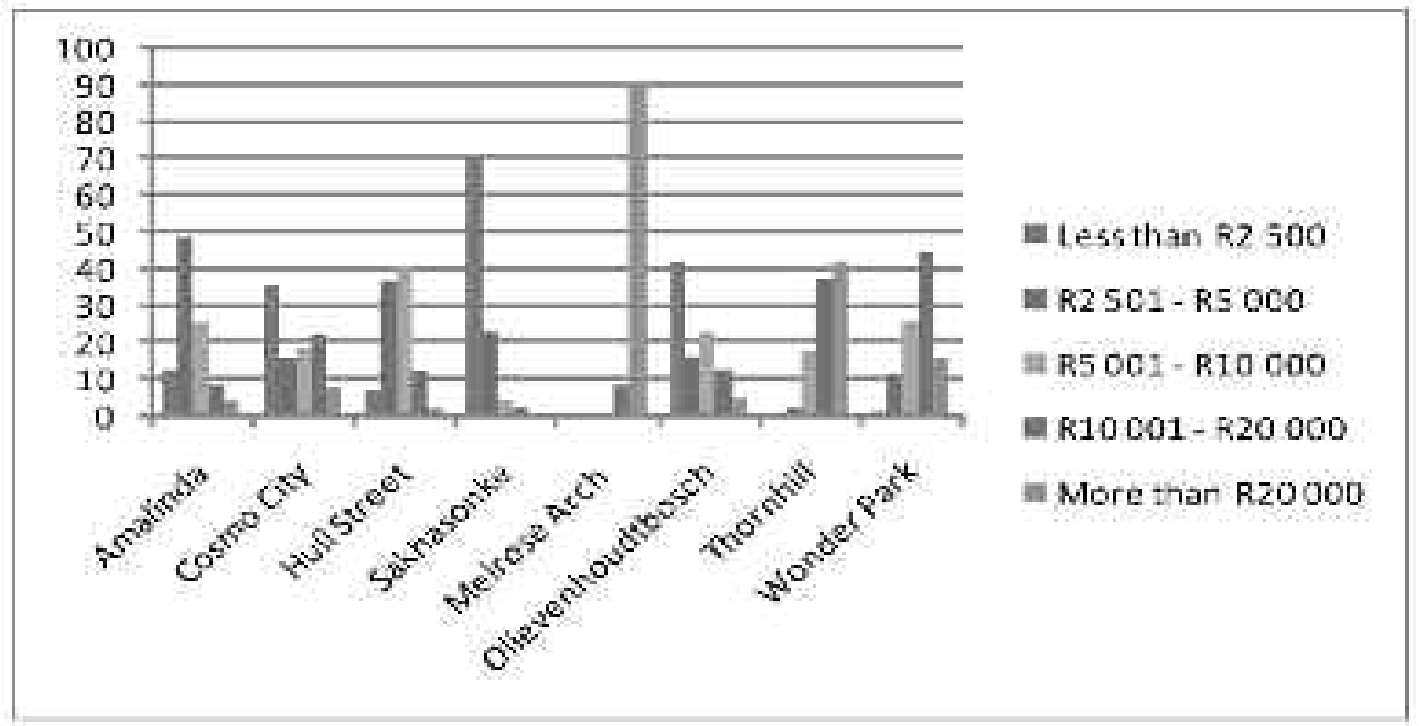

Figure 5. Households' earnings per month for eight case study areas.

3 The findings from Pennyville are excluded as the interviews were not representative of all the income groups as the housing for all the income groups had not been completed at the time of the interviews. 


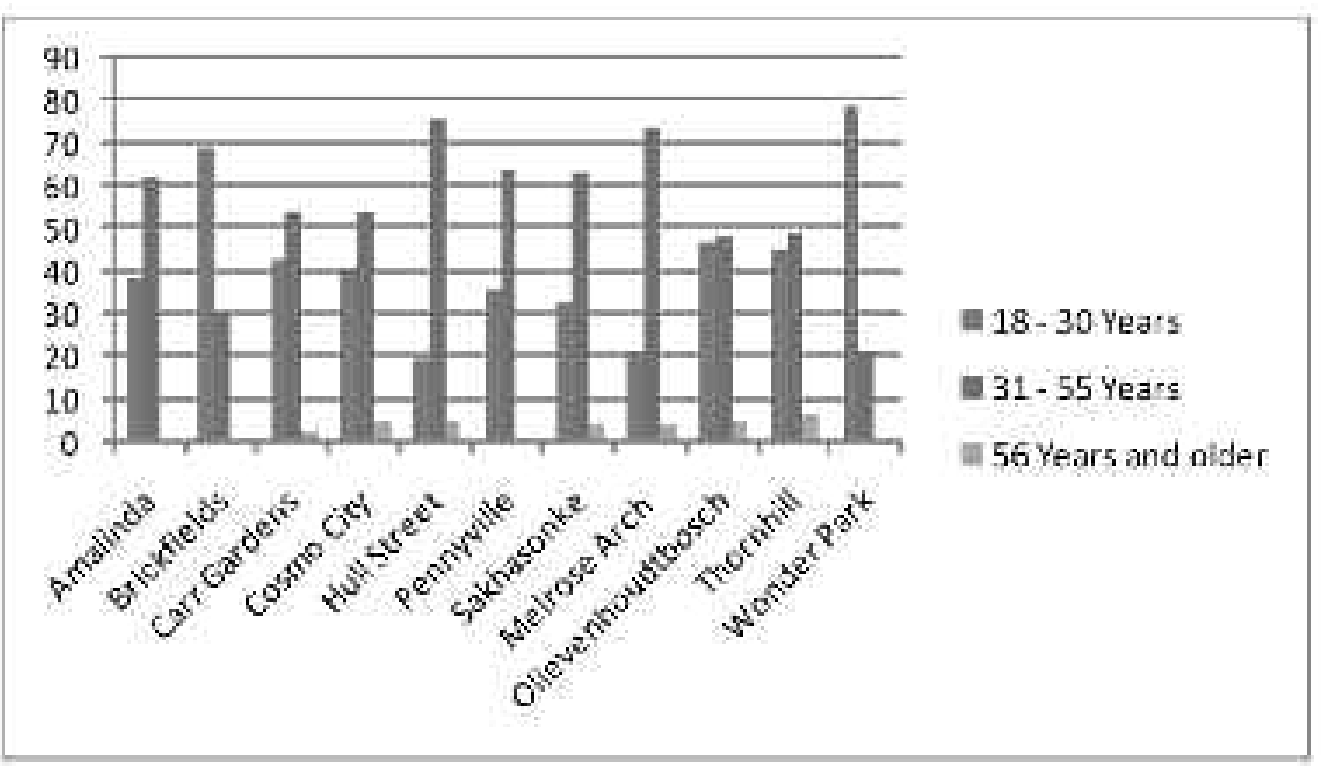

Figure 6. Age distribution within the projects.

modate only RDP units, about $20-40 \%$ of households in Cosmo City, Sakhasonke and Hull Street earned between R5000 and R10 000 per month, and about $10-20 \%$ earned between R10 000 and R20 000 per month. This is significant given that in 2010 the Bureau for Market Research in Stellenbosch indicated that the average household income in South Africa was R9 955. In addition, $57 \%$ off people in South Africa lives below the poverty line (Schwabe, 2004) ${ }^{4}$. A smaller percentage of households in Cosmo City, Olievenhoudbosh and Wonder Park even indicated that they earned more than R20 000 per month which starts to point towards a significant mix of income groups in these projects. In the case of Thornhill and Melrose Arch, a much larger percentage of people (between 40 and 90\%) indicated that they earned more than R20 000 per month, showing that people from higher income groups are willing to invest in medium density mixed income projects.

These projects also accommodated a mix of age groups (Figure 7). The questionnaire recorded the age of the adult person who completed the survey. Most of these persons were either between the ages of 18 and 30 years $(40 \%)$ or between 31 and 55 years (56\%). In addition, the majority of households in most of the cases included children under the age of 17 years, although the distribution differed between the cases study areas (Figure 8).

These developments also facilitated opportunities for social mix through a mix of population groups to some extent (Figure 9). Although this mix is not as high as the previous groups, it does start to show that some form of mix is possible within mixed developments, especially in projects such as Brickfields, Carr Gardens, Amalinda and Sakhasonke and to a larger extent in Thornhill and Melrose Arch. It also indicates that the type of mix may differ according to the type of project and the area in which it is located, for example the different distribution of population groups in Amalinda and Hull Street, and the thresholds of income groups targeted, for example Thornhill and Melrose Arch.

This indicates a move towards the implementation of the different design strategies for diversity in South Africa, which appears to support greater social mix in the various projects. However, in spite of this a few paradoxes remain.

\section{PARADOXES AND REALITIES IN NEW PROJECTS IN SOUTH AFRICA}

As was the case internationally and specifically in Chicago (Talen 2008), socio-spatial mix and

${ }^{4}$ Poverty estimates are calculated using a poverty line that varies according to household size. A household of 4 persons has a poverty income of R1 290 per month (Schwabe 2004) 


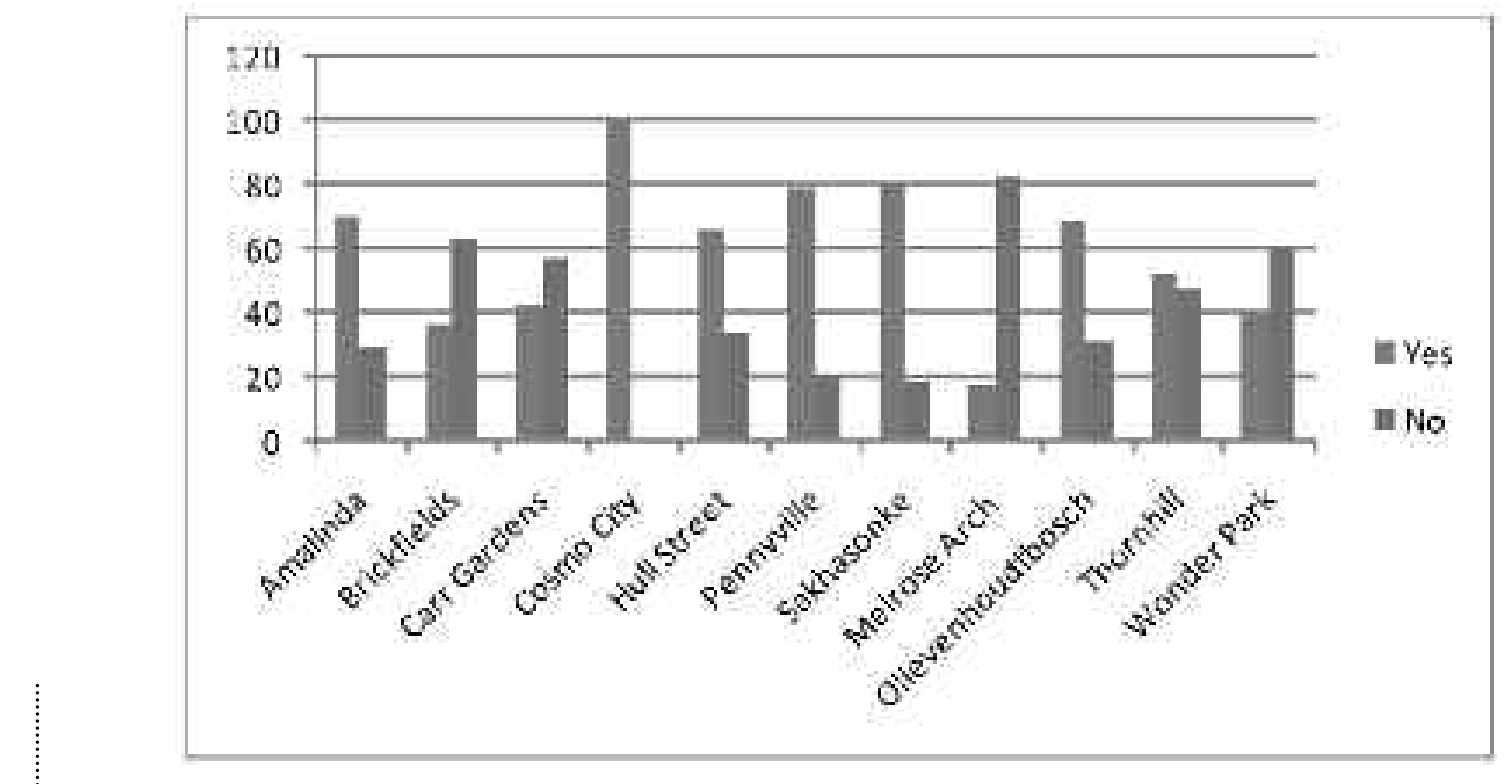

Figure 7. Households with children under the age of 17 years.

Figure 8. Distribution of population groups within the various developments.

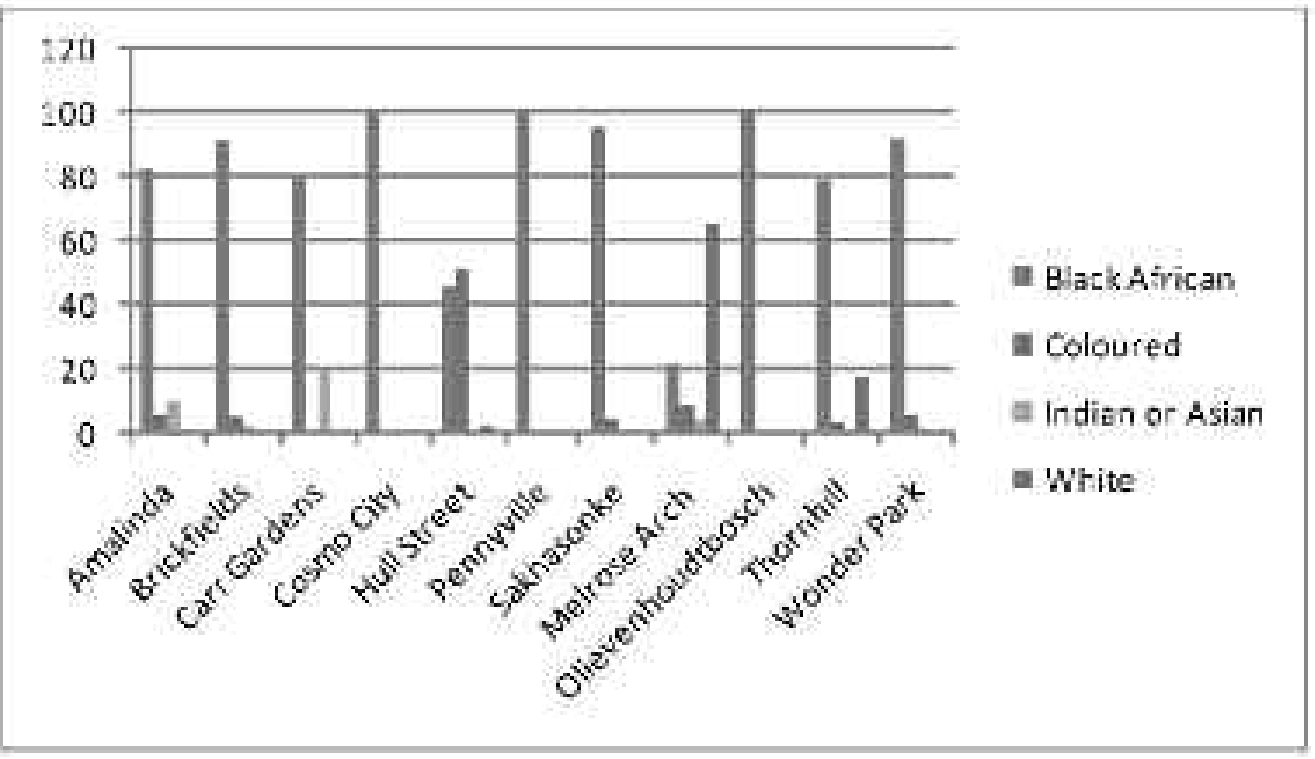

attempts towards diversity in South Africa has also been influenced by historical/ economical/social, policy-related and physical/ locational factors, which all have an interrelated effect on each other. This will be discussed briefly.

\section{Policies and preferences}

In reaction to the new housing plan, there has been an increased focus on the development of more inclusive housing developments, ranging from smaller integrated complexes to large mixed neighbourhoods. According to a set of spatial indicators 5 , most of these projects accommodates spatial mix through a mix of housing units/types, facilities and land uses in close proximity. As discussed, many also facilitate social mix through a range of income, age and population groups. As a result, these developments accommodate a much higher level of socio-spatial integration compared to previous housing and neighbourhoods developments in South Africa and in this way starts to address the inherent patterns of low-density sprawl, fragmentation and segregation, while facilitating

5 One of the methods included a spatial analysis of all the case study areas based on a spatial analysis tool developed to measure the spatial performance of these projects according to a set of principles and indicators. 
greater diversity within these urban spaces.

However, inherent in these development patterns hides a paradox, linked to the response of residents and the urban form to the realities of the social and cultural context. In spite of the incorporation of a number of design strategies to enhance safety and security6, residents indicated "safety and security" as the most important category of critical success factors in terms of preferences in the case study areas ${ }^{7}$. In addition, most of them highlighted the importance of target hardening and physical measures such as fences or walls around the development and controlled access. Therefore, while these developments have been able to facilitate greater integration and diversity within the area, many are still physically separated from their surrounding areas. It therefore highlights the paradox inherent between the normative goals of greater integration and security, which has direct implications for design strategies towards diversity. Therefore, as also pointed out by Talen (2008), as long as attempts towards diversity, even though promoted by policies, is seen to be conflicting with perceived strategies to accommodate greater security, it will remain a point of contention, especially given the high levels of crime and fear of crime in South Africa.

\section{Practice and power play}

As discussed, the type of mix within the new projects also differed according to the type of project, the area in which it is located and the thresholds of income groups targeted. In practice, the development of these projects is highly dependent on the input and engagement of various stakeholders. The projects with a large component of low-income and affordable housing is to a large extent dependent on the housing subsidies and support of the national government to guarantee bank loans for the credit-linked housing. Without this, it would not have been financially viable for the developers and/or housing agencies to accommodate a mix of housing types and income groups in the same development. At the same time, the success of these, especially those accommodating middle and higher income groups, are very dependent on the housing market and the willingness of these groups to invest in mixed developments. Therefore, although the aim is towards greater integration and diversity, the level of mix will be influenced to a large degree by the conditions of the housing and land market, including levels of affordability (for the state, private developers and potential residents) and the socio-economic and cultural context within these developments. In this sense, practices related to urban form and conscious spatial mix towards greater social mix, cannot be divorced from the contextual realities influencing subtle power plays between different stakeholders and the establishment of a so-called 'win-win' situation. Within these developments, the question in South Africa remains: a mix for who and why?

\section{Planning and physical design}

The findings have also indicated physical/locational factors can create more opportunities for diversity within the new medium density mixed housing projects. However, the extent to which it is possible to apply the three design strategies - mix, connectivity and security - will differ from place to place and depend on the socio-economic and cultural context influencing the urban form. The smaller the mixed development, the greater the limitation on the extent of socio-spatial mixes that can be achieved. However, on the other hand, larger, more exclusive developments, such as Melrose Arch, may target a specific group, and in this way accommodate less diversity in terms of social mix, while facilitating an extensive spatial mix. A significant spatial mix may therefore not always translate into a large social mix and as a result, only give rise to a selected type of diversity in practice or a mix of certain groups in specific demarcated urban spaces. Increased densities have, however, translated in increased access to a range of socio-economic and recreational opportunities for residents form these projects. Planning and designing for medium density mixed housing projects therefore creates an interesting paradox: while it facilities greater and/or selective diversity within these developments or neighbourhoods, it does not yet transcends the boundaries or edges of many of these developments and as such have some way to go to address patterns of spatial fragmentation and social separation at a larger city scale.

\footnotetext{
6These included a focus on surveillance, ownership and territoriality, image and aesthetics and target hardening.

7The questionnaires tested the importance of a range of critical success factors for medium density mixed housing based on five categories, namely affordability, design and layout, safety and security, neighbourliness and social cohesion and management and maintenance. 


\section{CONCLUSION: DIVERSE PLACES AND MEANINGS}

This paper conceptualised urban place diversity within the South African context and showed how this has been concretised within medium density mixed housing developments. The discussion highlighted the multiple meanings of diversity as related to various factors, namely socio-economic, policy and physical/locational. While South Africa does not have a strong tradition of catering for diversity, in spite of the presence of a diverse population in the country, the new medium-density mixed housing projects are starting to challenge this tradition. The findings have indicated that the presence of diversity within these projects is a result of both government policy and the willingness of key stakeholders to engage with this in practice.

However, due to the specific context realities within the country, such as high levels of crime and a legacy of separate development, a number of paradoxes remain. This relates to concerns regarding safety and financial viability, which has an influence on the level of integration within and beyond these developments. While the findings indicate that people are willing to accept greater levels of diversity within medium density mixed developments, it may take some time to transcend these boundaries and speak of significant diversity at a city scale. Then again, it may also be useful to engage in a debate on the relevance of urban space diversity at that scale and whether planners and urban designers should rather focus on neighbourhood diversity and its link to various social and spatial factors. Within the South African context, the achievement of greater diversity, albeit at a neighbourhood level and often selective, is already a major step ahead towards creating more sustainable and safer cities.

Finally, it can be concluded that the increased focus on diversity and incorporation of medium densities and a greater mix to facilitate this, can be considered as part of a larger global trend moving towards greater place diversity in cities, and at the same time as a specific attempt to address the a specific historical context in the country. The discussion highlighted many similarities in terms of international and local design strategies to accommodate mix. However, the inherent paradox- es which emerged indicates the presence of both historical and contemporary social and cultural influences that will take time to dissolve and pave the way for greater diversity within and beyond neighbourhoods in South African cities.

\section{Acknowledgements}

The author would like to acknowledge the CSIR for funding the initial research project and the contributions of the other team members, Gertrude Matsebe and Maema Mmonwa with data collection and analysis (household surveys) and $\mathrm{Dr}$ Jacques du Toit for the statistical analysis. In addition she would also like to acknowledge the contribution from the honours students, namely Martin Dam and Gerhard Koekemoer (Melrose Arch), Karla Booysen and Jacorien van Eeyssen (Olievenhoudtbosch), Tumelo Moila (Thornhill) and Sophie Ngobeni (Wonder Park).

\section{REFERENCES}

BAILY, N., HAWORTH, A., MANZI, T., PARANAGAMAGE, P., and ROBERTS, M., 2006, Creating and sustaining mixed income communities: A good practice guide. Published for the Joseph Rowntree Foundation, Chartered Institute of Housing UK.

BERUBE, A. 2005, Mixed communities in England: A US perspective on evidence and policy prospects. Joseph Rowntree Foundation, York.

BUREAU FOR MARKET RESEARCH, 2010, Household income in SA up 6,5\%. Property 24, 29 Nov 2010, Accessed on 4 January 2012 at http://www.property24.com/articles/household-income-in-sa-up-65/12758

BROPHY, C. P. and SMITH R. N. 1997, Mixed Income Housing: Factors for Success. Cityscape: A Journal of Policy Development and Research. Vol. 3/2: pp. 3-31.

DEWAR, D. 1992, Urbanization and the South African city: A manifesto for change. In Smith, D.M. (ed.). The apartheid city and beyond: Urbanisation and social change in South Africa. Routledge, London, pp. 205-215.

GEURS, K. T. and VAN WEE, B., 2006, Ex-post Evaluation of Thirty Years of Compact Urban Development in the Netherlands. Urban Studies. Vol. 43, pp. 139-160. 
HANHORSTER, H. 2001, Whose neighbourhood is it? Ethnic diversity in urban spaces in Germany, GeoJournal. Vol. 51, pp. 329-338.

JABAREEN, Y. R. 2006, Sustainable urban forms: their typologies, models and concepts. Journal of Planning Education and Research. Vol. 26/1, pp. 38-52.

JACOBS, J. 1961, The Death and Life of Great American Cities. Vinatge Books, New York.

JENKS, M. and DEMPSEY, 2005, Future Forms and Design for Sustainable Cities. Architectural Press, Oxford.

JOHNSTON, C. 2002, Housing Policy and Social Mix: An Exploratory Paper. Prepared for Shelter NSW, Sydney, Australia. Available on http:// www.shelternsw.infoxchange.net.au/docs/ rpt02socialmix-sb.pdf

LANDMAN, K. and DU TOIT, J. 2008, Case studies utilising mixed methods to research medium density mixed housing developments in South Africa. CSIR Report: Document Reference number: CSIR/BE/PSS/IR/2007/0015/B.

QUIGLEY, J. M. 1998, Urban diversity and economic growth. The Journal of Economic Perspectives. Vol. 12/2, pp. 127. 138.

ROGERS, R. 1997, Cities for a Small Planet. Butler and Tanner Ltd, London.

SCHWABE, G. 2004, Fact Sheet: Poverty in South Africa. Human Sciences Research Council, Pretoria. Accessed on 4 January 2012 at http://www.sarpn.org/documents/d0000990

SOUTH AFRICA - DEPARTMENT OF HOUSING, 2004, Breaking New Ground: A Comprehensive Plan for the Development of Sustainable Human Settlements. Prepared by the National Department of Housing, Pretoria.

TALEN, E. 2008, Design for Diversity: Exploring Socially Mixed Neighbourhoods. Architectural Press, Oxford.

WHEELER, S. M. 2000, Planning for metropolitan sustainability. Journal of Planning Education and Research. Vol. 20, pp. 133-145.
WHEELER, S. M. 2002, Infill development' from Smart Infill: Creating More Livable Communities in the Bay Area. In The Sustainable Urban Development Reader. Wheeler, S. M. and Beatley, T. 2004. Routledge, London.
Dr. Karina Landman

University of Pretoria

Department of Town \& Regional Planning

Private Bag X20 Hatfield, 0028,South Africa

karina.landman@up.ac.za 